\title{
EDITORIAL ALKITAB MENENTANG PERNIKAHAN SESAMA JENIS KELAMIN
}

\section{Antonius Steven Un}

Beberapa waktu lalu, Persekutuan Gereja-Gereja di Indonesia (PGI) mengeluarkan pernyataan dukungan terhadap pernikahan sesama jenis kelamin (homoseksualitas). ${ }^{1}$ Hubungan homoseksual yang dimaksud adalah "suatu ketertarikan istimewa erotis kepada pribadi manusia lain yang memiliki jenis kelamin yang sama yang biasanya - meski tidak selalu - disertai dengan hubungan seksual di antara mereka."2 Dalam pernyataan pastoral tersebut, antara lain berbunyi, "Berkenaan dengan LGBT$^{3}$, Alkitab memang menyinggung fenomena LGBT, tetapi Alkitab tidak memberikan penilaian moral-etik terhadap keberadaan atau eksistensi mereka. Alkitab tidak mengeritisi orientasi seksual seseorang. Apa yang Alkitab kritisi adalah perilaku seksual yang jahat dan eksploitatif yang dilakukan oleh siapa pun, termasuk yang dilakukan kaum heteroseksual, atau yang selama ini dianggap 'normal'." Bertolak belakang dengan pandangan PGI, Penulis meyakini bahwa Alkitab yang adalah firman Allah menentang homoseksualitas. Gordon Wenham mengatakan, "Homoseksualitas dikutuk di seluruh Alkitab (Kejadian 19; Imamat. 20:13; Hakim-hakim 19:22; Roma 1:27; 1 Korintus 6:9)". " Secara positif, homoseksualitas ditentang oleh tiga tatanan normatif dalam Alkitab yakni tatanan penciptaan, tatatan hukum Taurat dan tatanan

\footnotetext{
1 Lih. http://pgi.or.id/wp-content/uploads/2016/06/Pernyataan-Sikap-PGI-tentangLGBT.pdf. Diakses pada 4 Mei 2017.

2 Judd Marmor, "a definite preferential erotic attraction to members of the same sex and who usually (but not necessarily) engages in overt sexual relations with them". Lih. Judd Marmor, ed. Homosexual Behavior: a Modern Reappraisal (New York: Basic Books, 1980), 5. Dikutip oleh John J. Davis, Evangelical Ethics: Issues Facing the Church Today (Phillipsburg: Presbyterian and Reformed, 1993), 95-96.

3 LGBT adalah kependekan dari lesbian, gay, bi-seksual dan trans-gender.

4 "Homosexuality is condemned throughout Scripture". Gordon Wenham, The Book of Leviticus, NICOT (Grand Rapids: Eerdmans, 1979), 259.
} 
kehidupan Kerajaan Allah menurut Perjanjian Baru, khususnya SuratSurat Paulus.

Tatanan penciptaan yang dicatat dalam Kejadian 1-2 menyatakan bahwa Tuhan sejak awal merancang pernikahan antara dua insan manusia yang berbeda jenis kelamin. Kejadian 1:27 menyatakan bahwa Tuhan menciptakan laki-laki dan perempuan. Kejadian 2:22-25 menyatakan bahwa Tuhan memersatukan laki-laki dan perempuan. Sebagai gambar Allah, keberbedaan (diversity) secara seksual (gender) menggambarkan adanya keberbedaan dalam diri Allah Tritunggal di mana Pribadi Bapa, Anak dan Roh Kudus berbeda satu dengan lainnya. Keberbedaan secara seksual (gender diversity) sebagaimana dinyatakan dalam tatanan penciptaan merupakan keberbedaan yang mendasar (primal), kasat mata dan ontologis. Keberbedaan secara seksual paling mudah ditemukan, bahkan tanpa penelitian ilmiah sekalipun. Tidak heran, pernikahan heteroseksual merupakan gambaran sempurna dari Allah Tritunggal yang citra-Nya dilekatkan pada manusia. Di dalamnya berlaku prinsip diversity but unity (berbeda namun tetap satu). Sebaliknya, hubungan homoseksual telah menggantikan diversity but unity dengan uniformity (keseragaman) di mana terjadi persatuan antara dua pribadi yang sama-sama jenis kelamin dan karakteristiknya. Filsuf Hannah Arendt mengatakan bahwa bentuk paling dasar keragaman (plurality) sudah ada ketika laki-laki dan perempuan diciptakan oleh Tuhan. ${ }^{5}$ Arendt mengutip Kejadian 1:27: "laki-laki dan perempuan diciptakanNya mereka".

Lembaga pernikahan yang dirancang oleh Tuhan melalui tatanan pernikahan bukanlah sekedar lembaga pro-kreasi. Tatanan Tuhan bagi lembaga pernikahan memang melibatkan tugas perkembang-biakan. Namun demikian, multiplikasi tersebut sesungguhnya adalah multiplikasi gambar Allah. Keinginan Tuhan agar manusia sebagai gambar Allah menguasai alam ciptaan Tuhan dalam tugas pemeliharaan

\footnotetext{
5 Hannah Arendt, The Human Condition (Chicago \& London: the University of Chicago Press, 1998 [1958)), 7-8.
} 
dan pengelolaan diwujudkan melalui multiplikasi gambar Allah. Karena itu, rancangan Tuhan bagi pernikahan heteroseksual lebih dari sekedar perkembang-biakan ras manusia tetapi lebih untuk multiplikasi gambar Allah. Dalam rangka multiplikasi gambar Allah maka pernikahan heteroseksual bukan saja berfungsi untuk perkembang-biakan manusia tetapi juga untuk memultiplikasi gambar Allah yang utuh melalui model citra diversity but unity yaitu dua insan yang berbeda jenis kelamin namun dipersatukan oleh Tuhan. Hal ini merupakan turunan dari Allah Tritunggal, tiga Pribadi namun tetap satu.

John Frame mengatakan bahwa perbedaan laki-laki dan perempuan adalah hal yang sangat penting bagi makna pernikahan. ${ }^{6}$ Dalam Efesus 5:22-33, laki-laki mewakili Kristus dan perempuan mewakili gereja. Posisi gereja dan Kristus yang berbeda tidak perlu dikacaukan atau dikaburkan. Namun demikian, dalam homoseksualitas, perbedaan tersebut tidak ada dalam dua insan yang sama jenis kelaminnya. Dengan demikian, bila kita menggunakan penggambaran Efesus 5:22-33, dalam homoseksualitas, posisi Kristus dan gereja yang berbeda justru diseragamkan atau dipertukarkan (interchangeable). Bagi Frame, hal ini bukan saja salah melainkan "akar dari semua dosa - suatu kesesatan utama."7

Selain itu, Kejadian 2:18 menyatakan bahwa perempuan dicipta sebagai penolong yang sepadan. Tuhan menciptakan Adam sebagai gambar Allah yang sempurna namun bukan merupakan gambar Allah yang tak terbatas. Adam adalah gambar Allah yang sempurna namun tidak tak terbatas. Karena itu, keterbatasan itu dilengkapi oleh keberadaan Hawa, sang perempuan yang diangkat oleh Tuhan menjadi "penolong yang sepadan". Kehadiran sebagai penolong tidak merendahkan status Hawa karena bagaimanapun Adam dicipta dari debu tanah tetapi Hawa dicipta dari tulang rusuk Adam. Selain itu,

\footnotetext{
6 John M. Frame, The Doctrine of the Christian Life (Phillipsburg: Presbyterian and Reformed, 2008), 759.

7 Ibid. Frame, "But symbolically, this suggests that God and man are interchangeable. And that notion is not only wrong, but the root of all sin - the primal heresy."
} 
justru gambar Allah pada Adam tidak lengkap bila tidak ada Hawa. Tidak heran, Tuhan sendiri berkata, "Tidak baik manusia itu seorang diri saja". Keunikan laki-laki dan keunikan perempuan digabungkan oleh Tuhan untuk menjadi sebuah kekuatan yang luar biasa dalam rangka menjalankan misi Tuhan.

Tatanan penciptaan ini dikonfirmasi oleh hukum Taurat. Hukum Taurat pada hakekatnya merupakan penataan ulang yang dilakukan oleh Tuhan terhadap kehidupan umat Tuhan yang telah dibebaskan dari perbudakan di tanah Mesir. Secara logis, tatanan Tuhan sulit diaplikasikan oleh umat Tuhan yang berada di bawah perbudakan oleh bangsa lain. Penataan ini menyangkut hubungan antara manusia dengan Allah (hukum 1-4 dari 10 Hukum Taurat) dan hubungan manusia dengan manusia (hukum 5-10). Dalam konteks pelarangan terhadap perzinahan, hukum Taurat juga menentang homoseksualitas dalam Imamat 18:22 dan 20:13. Dengan demikian, pelarangan terhadap homoseksualitas dalam hukum Taurat merupakan bagian dari hukum moral yang berkesinambungan hingga ke masa kini karena hukum moral itu sendiri dikonfirmasi oleh Kristus.

Dalam Imamat 18:22, Tuhan berkata, "Janganlah engkau tidur dengan laki-laki secara orang bersetubuh dengan perempuan, karena itu suatu kekejian". Dalam tafsiran terhadap ayat ini, Robert M. Paterson mengatakan, "Hubungan homoseks dilarang. Hukuman disebut dalam 20:13. Kekejian: Yaitu suatu yang keji, baik dari sudut agama maupun dari sudut moral". ${ }^{8}$ Dalam tafsiran ayat 23 tentang "perbuatan keji", Paterson menjelaskan, "Kata bahasa Ibrani ini...menunjuk kepada perbuatan keji yang mengotori, menyebabkan kekacauan, dan melawan kehendak serta rencana Allah untuk dunia". 9 Sejalan dengan Paterson, Wenham mengatakan bahwa istilah "kekejian" (Ibrani: tô 'ébah) dalam ayat 22 yang digunakan sebanyak lima kali dalam pasal 18 ini (ayat 22, 26, 27, 29, 30)

\footnotetext{
Robert M. Paterson, Kitab Imamat (Jakarta: Gunung Mulia, 1997), 251.

Paterson, Kitab Imamat, 252.
} 
merupakan "istilah ketidaksetujuan yang keras dalam bahasa Ibrani". ${ }^{10}$ Akar kata ini, kata Wenham, adalah "membenci" (to hate). ${ }^{11}$ Karena itu, perbuatan yang dianggap kekejian haruslah merupakan perbuatan yang dibenci oleh Allah. Dengan demikian, dalam Imamat 18:22, "homoseksualitas jelas ditentang." 12

Sejalan dengan tatanan penciptaan dan tatanan hukum Taurat, tatanan kehidupan dalam Kerajaan Allah tidak memerbolehkan adanya hubungan homoseksualitas. Roma 1:2713, 1 Korintus 6:914, dan 1 Timotius 1:1015 menyatakan hal ini dengan jelas. Dalam 1 Korintus 6:9, Paulus menyatakan bahwa orang-orang yang tidak benar-adil (Yunani: adikoi) tidak akan mewarisi Kerajaan Allah. Di antara mereka termasuk pelaku homoseksualitas (LAI Terjemahan Baru: "pemburit"). Alkitab English

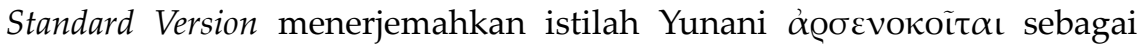

10 Wenham berkata, "[A] term of strong disapproval in Hebrew". Lih. Wenham, Leviticus, 259.

11 Wenham, Leviticus, 259.

12 Allen P. Ross berkata, "Homosexuality is clearly prohibited, here (18:22) and elsewhere in Scripture (Lev. 20:13; Rm. 1:27; 1 Kor. 6:9)" (Allen P. Ross, Holiness to the LORD: a Guide to the Exposition of the Book of Leviticus (Grand Rapids: Baker Academic, 2002), 346).

Bandingkan, John E. Hartley berkata, "Homosexuality is forbidden (20:13; cf. Rm 1:27; 1 Kor. 6:9), being classified as detestable" (John E. Hartley, Leviticus, WBC (Dallas: Word Books, 1992), 297).

13 LAI Terjemahan Baru: “Demikian juga suami-suami meninggalkan persetubuhan yang wajar dengan isteri mereka dan menyala-nyala dalam berahi mereka seorang terhadap yang lain, sehingga mereka melakukan kemesuman, laki-laki dengan laki-laki, dan karena itu mereka menerima dalam diri mereka balasan yang setimpal untuk kesesatan mereka." 14 LAI Terjemahan Baru: "Atau tidak tahukah kamu, bahwa orang-orang yang tidak adil tidak akan mendapat bagian dalam Kerajaan Allah? Janganlah sesat! Orang cabul, penyembah berhala, orang berzinah, banci, orang pemburit". English Standard Version: "Or do you not know that the unrighteous will not inherit the kingdom of God? Do not be deceived: neither the sexually immoral, nor idolaters, nor adulterers, nor men who practice homosexuality".

15 LAI Terjemahan Baru: "bagi orang cabul dan pemburit, bagi penculik, bagi pendusta, bagi orang makan sumpah dan seterusnya segala sesuatu yang bertentangan dengan ajarah sehat". English Standard Version: "the sexually immoral, men who practice homosexuality, enslavers, liars, perjurers, and whatever else is contrary to sound doctrine". Karena alasan praktis keterbatasan tempat, Penulis belum membahas ayat ini. Glen H. Stassen \& David P. Gushee mengatakan, “Dalam 1 Timotius, pembicaran berkenaan dengan pemakaian hukum secara legitimat untuk menyalahkan berbagai praktik imoral, yang di antaranya termasuk perilaku homoseksual" (Lih. Glen H. Stassen \& David P. Gushee, Etika Kerajaan: Mengikuti Yesus dalam Konteks Masa Kini, terj. Peter Suwadi Wong (Surabaya: Momentum, 2005), 396). 
"men who practice homosexuality" (para laki-laki yang menjalankan homoseksualitas). Gagasan dari ayat ini adalah bahwa tatanan kehidupan dalam Kerajaan Allah tidak memerbolehkan adanya hubungan homoseksualitas. Orang-orang yang tidak benar-adil tersebut bukan saja tidak mewarisi Kerajaan Allah namun bahkan mereka akan dihakimi dan inilah alasan penghakimannya. ${ }^{16}$ Bagi James D.G Dunn, penolakan Paulus terhadap hubungan seksual yang menyimpang termasuk homoseksualitas dan imoralitas seksual secara umum adalah hal yang signifikan karena merupakan penanda penting keunikan gereja Yesus Kristus dibandingkan dengan ajaran sesat atau etika yang lazim pada masa itu. ${ }^{17}$

Gordon Fee memerlihatkan adanya ketegangan soal penerjemahan istilah Yunani arsenokoitai. ${ }^{18}$ Istilah ini memang terdiri dari dua kata "laki-laki" dan "hubungan seksual". Namun Fee berpandangan bahwa istilah ini dapat diterjemahkan sebagai "laki-laki yang berhubungan seksual" dan dengan demikian menunjuk kepada semua prostitusi lakilaki secara umum. Istilah ini juga dapat diterjemahkan sebagai "berhubungan seksual dengan laki-laki" dan dengan demikian berbicara soal homoseksualitas pria. Bila kita memerhatikan konteks ayat ini, di mana Paulus sedang mendaftarkan perilaku yang tidak boleh merupakan bagian dari Kerajaan Allah, homoseksualitas tentu termasuk di dalamnya, mengingat Paulus juga menentang homoseksualitas pada tulisannya yang lain (Roma 1:27). David E. Garland menambahkan bahwa terdapat kemungkinan sangat kuat Paulus dipengaruhi oleh Imamat 18 dan 20 dalam tulisan ini. ${ }^{19}$ Bila Paulus menegur dengan keras pernikahan antara keluarga (konteks dekat yakni pasal 5) sementara hubungan inses dilarang dalam Imamat 18:7-8 dan 20:11 maka tidak berlebihan bila

\footnotetext{
16 Gordon D. Fee, "The failure of the wicked to "inherit the kingdom of God" is the other side of their being judged in v.2; this is what that judgment leads to". Lih. Gordon D. Fee, The First Epistle to the Corinthians (Grand Rapids: Eerdmans, 1987), 242.

17 James D. G Dunn, The Theology of Paul, the Apostle (Grand Rapids: Eerdmans, 1998), 690.

18 Fee, First Corinthians, 244.

19 David E. Garland, 1 Corinthians, BECNT (Grand Rapids: Baker Academic, 2003), 212-213.
} 
Imamat 18:22 dan 20:13 memengaruhi Paulus dalam menentang hubungan homoseksualitas. Dengan demikian, Garland memahami istilah Yunani arsenokoitai dalam konotasi pernikahan sesama jenis kelamin. Pandangan Garland diperkuat oleh faktor kuatnya pengaruh terjemahan LXX dari Imamat 20:13 kepada pembentukan istilah arsenokoitai yang digunakan tiga kali oleh Paulus. ${ }^{20}$ Terjemahan LXX dari



Selain 1 Korintus 6:9, Paulus juga menentang hubungan homoseksualitas dalam Roma 1:27. Konteks dari ayat ini adalah pemaparan kehidupan manusia berdosa yang selayaknya mendatangkan hukuman Allah. Paulus memaparkan keberdosaan manusia dalam 1:183:20 di mana Paulus membicarakan dosa-dosa orang non-Yahudi 1:18-32 sebelum membicarakan dosa-dosa orang Yahudi dalam bagian selanjutnya. Sebagaimana lazimnya dipahami, surat Roma ditulis oleh Paulus di kota Korintus. ${ }^{22}$ Tidak heran, bayangan dosa-dosa yang ada di kota Korintus sangat mungkin terlintas di pikirannya tatkala ia menulis bagian 1:18-32.

Dalam tafsirannya atas Roma 1:27, van den End menyebut hubungan homoseksualitas sebagai "penyelewengan". ${ }^{23}$ Roma 1:27 sendiri menyebut hubungan sesama jenis kelamin ini sebagai “kesesatan". Leon Morris menerjemahkan kata Yunani $\pi \lambda \alpha \dot{v} v\rceil \varsigma$ sebagai "error". 24 Selain kesesatan, hubungan homoseksual juga disebut sebagai persetubuhan yang tak wajar. Thomas Schreiner menjelaskan, "Bahwa hubungan homoseksual bertentangan secara alamiah dalam pengertian bahwa hubungan tersebut telah merusakkan apa yang dirancang oleh Allah." 25 Schreiner menyimpulkan, "Ayat 27 tidak memberi indikasi

\footnotetext{
20 Gagasan ini diperoleh Penulis dari masukan David Tong setelah membaca artikel editorial ini.

21 Lih. https://www.blueletterbible.org/lxx/lev/20/1/s_110001. Diakses pada 5 Mei 2017.

22 Th. van den End, Surat Roma (Jakarta: Gunung Mulia, 1997), 3.

23 Van den End, Surat Roma, 79.

24 Leon Morris, The Epistle to the Romans, PNTC (Grand Rapids: Eerdmans, 1988), 93.

25 "That homosexual relations are contrary to nature, in the sense that they violate what God intended". Lih. Thomas Schreiner, Romans, BECNT (Grand Rapids: Baker Academic,
} 
bahwa hanya jenis tertentu dari homoseksualitas yang dilarang. Sebaliknya, hubungan homoseksual secara umum dipersalahkan." 26 Dengan demikian, bukan hanya hubungan homoseksual antara laki-laki yang dipersalahkan, namun Paulus juga mengeritik hubungan seksual antara sesama perempuan. Sejalan dengan gagasan ini, Glen H. Stassen \& David P. Gushee mengatakan, “Ketika menguraikan apa yang jelas-jelas ia pikirkan sebagai kubangan berbagai perilaku moral dan tidak wajar yang menjijikan, ia mengangkat tindakan homoseksual - baik antarapria maupun antarawanita - untuk diberi perhatian khusus (Roma 1:26-27)."27

Schreiner menolak pandangan bahwa hubungan homoseksual yang dipersalahkan oleh Paulus adalah hubungan yang dilakukan oleh mereka yang sesungguhnya merupakan pribadi-pribadi heteroseksual. ${ }^{28}$ Tafsiran ini harus ditolak, karena bagi Schreiner, "tidak ada bukti bahwa Paulus memahami hal yang alamiah dari manusia dalam pengertian terindividualisasi dan psikologis seperti yang lazim pada abad 20 ini." 29 Sebaliknya, kata Schreiner, "Bagi mereka yang menerima penjelasan Paulus sebagai kebenaran yang otoritatif (sebagaimana juga saya menerima), penolakan terhadap hubungan-hubungan homoseksual adalah jalan kepada kebahagiaan dan kekudusan." 30

Bila Alkitab jelas menentang hubungan homoseksual, apakah Alkitab membiarkan adanya hubungan sesama jenis kelamin antara Rut dengan Naomi serta Daud dengan Yonatan? Penelaahan yang hati-hati terhadap teks-teks dimaksud menyimpulkan bahwa sesungguhnya tidak pernah terjadi hubungan homoseksual antara Rut dengan Naomi dan Daud dengan Yonatan. Ada anggapan bahwa Rut dan Naomi

\footnotetext{
1998), 94 .

26 Schreiner, Romans, 95.

27 Stassen \& Gushee, Etika Kerajaan, 397.

28 Schreiner, Romans, 95.

29 "[T]here is no evidence that Paul understood the "nature" of human beings in the individualized and psychological sense that is familiar to us in the twentieth century". Lih. Schreiner, Romans, 95-96.

30 "For those who accept the Pauline proscription as authoritative (as I do), avoidance of homosexual relations is the path of happiness and holiness". Lih. Schreiner, Romans, 97.
} 
sesungguhnya mempunyai hubungan lebih dalam dari sekedar menantumertua karena Rut 1:14 menyatakan bahwa Rut berpaut kepada Naomi. ${ }^{31}$ Bukankah istilah Ibrani " $d b q$ " + prepossition " $b$ " juga digunakan dalam Kejadian 2:24 di mana digambarkan bahwa Adam bersatu (berpaut) dengan Hawa dalam pengertian hubungan seksual? ${ }^{32}$

Sesungguhnya istilah yang sama juga muncul dalam Rut 2:8, 21, 23, ketika Boas meminta Rut untuk tetap dekat (New King James Version: stay close) dengan pengerja-pengerja perempuan, tentu demi keamanan dari Rut sendiri. Jadi, tidak dapat dipaksakan bahwa kata kerja tersebut memiliki konotasi hubungan seksual antara Rut dan Naomi. K. Lawson Younger, Jr memahami ayat sebagai gambaran "firm loyalty and deep affection" (loyalitas tetap dan perasaan mendalam) serta "commitment" dari Rut kepada Naomi. ${ }^{33}$ Hal ini sejalan dengan terjemahan LXX, èkolouthēsen, yang berarti "she followed after" (Rut berjalan mengikuti Naomi). ${ }^{34}$ F.B Huey, Jr mengatakan bahwa kata kerja $d b q$ dapat dipahami sebagai suatu ekspresi atas "the ideal closeness" (kedekatan yang ideal) yang dapat berlaku bagi pernikahan tetapi juga bagi hubungan antara manusia. ${ }^{35}$

Dalam penelitiannya, George J. Brooke menemukan bahwa tiga kali istilah $d b q$ digunakan dalam asosiasi dengan cinta (Kejadian 34:3; 1 Raja-raja 11:2; Amsal 18:24). ${ }^{36}$ Meski demikian, hanya pertama dan kedua yang berasosiasi dengan hubungan suami istri yakni ketika Sikhem jatuh cinta kepada Dina, anak Yakub (Kejadian 34:3) dan ketika Salomo mencintai banyak perempuan asing (1 Raja-raja 11:2). Amsal 18:24 justru memakai kata ini dalam hubungan persahabatan karib antara sesama

\footnotetext{
31 LAI Terjemahan Baru: “Menangis pula mereka dengan suara keras, lalu Orpa mencium mertuanya itu minta diri, tetapi Rut tetap berpaut padanya."

32 Lih. penjelasan K. Lawson Younger, Jr, Judges/Ruth, NIVAC (Grand Rapids: Zondervan, 2002), 423.

33 Younger, Judges/Ruth, 423.

34 Edward F. Campbell, Jr, Ruth, The Anchor Bible (New York: DoubleDay, 1975), 72.

35 F.B Huey, Jr, "Ruth" in the Expositor's Bible Commentary, ed. Frank E. Gaebelein, 12 vols (Grand Rapids: Zondervan, 1992), III: 522.

36 George J. Brooke, "dbq" in New International Dictionary of Old Testament Theology $\mathcal{E}$ Exegesis, ed. Willem A. VanGemeren, 5 vols (Grand Rapids: Zondervan, 1997), I: 911.
} 
anak manusia. ${ }^{37}$ Selain itu, ada lebih banyak lagi penggunaan istilah ini di Alkitab yang sama sekali tidak berkaitan dengan urusan seksual. Misalnya, tangan "melekat" pada pedang (2 Samuel 23:10) dan ikat pinggang "melekat" pada pinggang (Yeremia 13:11).

Jadi, istilah "berpaut" yang digunakan dalam Rut 1:14 sesungguhnya menggambarkan loyalitas dan komitmen Rut terhadap mertuanya, justru ketika Naomi tidak mempunyai siapa-siapa lagi.

Bagaimana dengan hubungan Daud dan Yonatan? 1 Samuel 18:1 menyatakan, "Ketika Daud habis berbicara dengan Saul, berpadulah jiwa Yonatan dengan jiwa Daud; dan Yonatan mengasihi dia seperti jiwanya sendiri". Ralph W. Klein menyatakan bahwa cinta kasih Daud dan Yonatan bersifat "political and personal" 38 yaitu loyalitas politis dan perasaan pribadi (political loyalty and personal affection). ${ }^{39}$ Persahabatan pribadi yang dibangun antara Daud dan Yonatan akan berdampak dalam pemeliharaan keluarga misalnya Daud memerhatikan keturunan Yonatan (2 Samuel 9; 21:7). Loyalitas politis tampak misalnya dalam pembelaan Yonatan kepada Daud di hadapan Saul (1 Samuel 19). Ronald F. Youngblood mengatakan bahwa istilah bahasa Ibrani $\bar{a} h \bar{e} \underline{b}$ (love) tidak pernah dipakai di bagian manapun di Perjanjian Lama untuk menggambarkan keinginan atau aktivitas homoseksual. ${ }^{40}$ Sementara itu, istilah yād $a^{\prime}$ (know) dalam pengertian berhubungan seksual (Kejadian 19:5; Hakim-hakim 19:22) tidak pernah digunakan dalam hubungan Daud dengan Yonatan. Jadi, ayat ini tidak dapat dipaksakan untuk dipahami dalam hubungan homoseksual antara Daud dan Yonatan.

Dalam 2 Samuel 1:26, ketika meratapi kematian Yonatan, Daud

\footnotetext{
37 Duane A. Garrett menjelaskan, "Even so, there are some faithful friends who remain supportive in times of crisis (18:24), and poverty with moral dignity is preferable to wealth without character (19:1)" (Lih. Duane A. Garrett, Proverbs, Ecclesiastes, Song of Songs, NAC (Nashville: Broadman, 1993), 171). Bandingkan, R. Murphy \& E. Huwiler menyatakan, "[O]ne good solid friend is better than having many companions" (Lih. R. Murphy \& E. Huwiler, Proverbs, Ecclesiastes, Song of Songs, NIBC (Peabody: Hendrickson, 1999), 92.

38 Ralph W. Klein, 1 Samuel, WBC (Waco: Word Books, 1983), 182.

39 P. Kyle McCarter, Jr, 1 Samuel, The Anchor Bible (New York: DoubleDay, 1980), 305.

40 Ronald F. Youngblood, "1, 2 Samuel” in The Expositor's Bible Commentary, ed. Frank E. Gaebelein, 12 vols (Grand Rapids: Zondervan, 1992), III: 706.
} 
berkata, "Merasa susah aku karena engkau, saudaraku Yonatan, engkau sangat ramah kepadaku; bagiku cintamu lebih ajaib dari pada cinta perempuan". Di sini, Daud menyebut Yonatan sebagai "saudara", bukan sebagai kekasih. Jadi, ayat ini menggambarkan hubungan persahabatan yang begitu mirip dengan hubungan persaudaraan. A.A Anderson mengingatkan agar ayat ini jangan segera ditafsirkan sebagai adanya hubungan homoseksual antara Daud dan Yonatan. Terdapat empat alasan yang dikemukakan oleh Anderson. ${ }^{41}$ Pertama, bahwa sikap negatif seluruh Perjanjian Lama terhadap homoseksualitas mengindikasikan bahwa eksegesis ini bersifat tidak mungkin. Paling tidak, tidak mungkin teks ini membiarkan tanpa penilaian negatif atas hubungan homoseksualitas yang jelas menyimpang menurut tatanan hukum Taurat. Kedua, jangan lupa sifat puitis dari ayat ini. Sifat puitis menjadikan pembaca tidak langsung memahami perkataan ini seperti suatu pembacaan atas catatan sejarah. Ketiga, jangan lupa fakta kehidupan seksual Daud yang bersifat tertarik kepada wanita (heteroseksual). Keempat, lagipula, cinta perempuan tidak harus sematamata dipahami sebagai cinta seorang istri. Bisa juga cinta seorang ibu.

Jadi, penulis bersama para sarjana Perjanjian Lama dan Perjanjian Baru yang dilibatkan dalam tulisan ini menolak penafsiran sewenangwenang terhadap narasi Rut dan Daud bahwa seolah-olah terdapat hubungan homoseksual antara Rut dengan Naomi dan Daud dengan Yonatan. Adalah sesuatu yang reduktif dan arbitrer bila semua hubungan kasih persahabatan atau persaudaraan langsung dicurigai sebagai hubungan sesama jenis kelamin yang mendalam. Terdapat banyak kesaksian bahwa ada persahabatan sejati yang tidak pernah terkontaminasi oleh hubungan seksual. Terdapat juga banyak kesaksian bahwa ada persaudaraan sejati yang tidak pernah melibatkan urusan ranjang.

Berdasarkan pemaparan ini, dapat disimpulkan bahwa tatanan penciptaan, tatanan hukum Taurat dan tatanan pola hidup dalam

41 A.A Anderson, 2 Samuel, WBC (Dallas: Word Books, 1989), 19. 
Kerajaan Allah sebagaimana dinyatakan dalam Perjanjian Baru bersifat menentang homoseksualitas. Demikian pula pandangan bahwa adanya hubungan homoseksual antara Rut dengan Naomi dan Daud dengan Yonatan merupakan penafsiran yang liar dan sewenang-wenang atas teks Alkitab. Meski Alkitab dengan keras menentang homoseksualitas, sebagai anak-anak Tuhan, tugas kita adalah mengasihi dan mendoakan saudara-saudara kita umat manusia yang untuk sementara waktu belum dapat menerima prinsip-prinsip Alkitab. Kiranya Roh Kudus yang adalah Roh Kebenaran, yang mewahyukan Alkitab ke dalam dunia, dapat mengiluminasi pikiran saudara-saudara kita dan menguatkan mereka untuk hidup kudus dan menerima pengajaran Alkitab bahwa hubungan seksual yang benar adalah hubungan antara pria dan wanita (berbeda jenis kelamin), monogami (bukan poligami) dan dalam lembaga pernikahan yang disahkan oleh Tuhan dan diakui oleh negara.

\section{Jurnal Verbum Christi, Volume 4, Nomor 1, April 2017}

Titik berangkat gagasan pernikahan heteroseksual yang dibangun dalam tulisan ini adalah tatanan penciptaan (order of creation). Sesungguhnya, tatanan penciptaan tidak dibatasi hanya dalam hal pernikahan dan keluarga. Tatanan penciptaan juga mengatur soal kerja dan panggilan. Jadi S. Lima menguraikan secara komprehensif gagasan tentang panggilan dan kerja dengan memperhitungkan secara cermat peran tatanan penciptaan. Ia juga melibatkan pemikiran Martin Luther dan John Calvin dalam diskusi kultural ini. Pelibatan ini menghangatkan pembaca akan pemikiran Reformasi yang sedang dirayakan secara luas dalam peringatan 500 tahun pada tahun ini.

Bila Lima membicarakan pemikiran Reformasi sebagai bagian dari keseluruhan karya yang komprehensif, Charles F. Marunduri menelaah secara lebih spesifik pemikiran Martin Luther tentang teologi doa. Artikel Marunduri di awal jurnal dan artikel Lima di akhir jurnal yang menyinggung pemikiran Reformator Gereja abad 16 seolah menjadi lonceng gereja-gereja tua di Eropa yang memanggil pembaca untuk 
segera memikirkan kembali pemikiran Protestan awal. Dalam diskursus tentang homoseksual, teologi doa Luther yang dibahas memberikan arahan sistematis dalam mendoakan kaum homoseksual. Mendoakan mereka merupakan tanggung jawab suci orang percaya yang sesuai dengan kehendak Allah. Mendoakan mereka haruslah merupakan ungkapan yang benar-benar tulus dari dalam hati yang merindukan pertobatan dan pemulihan mereka. Apalagi, bukan rahasia bahwa saudara-saudara kita yang berada dalam keadaan demikian, sungguh memiliki banyak pergumulan.

Salah satu pergumulan yang dialami oleh para individu yang menjalankan praktek homoseksualitas adalah pengenalan akan diri. Gagasan Kierkegaard tentang pengenalan akan diri, sebagaimana diuraikan oleh Ivan Kristiono, menjadi penting di sini. Filsuf Denmark ini menawarkan model ideal yang hendak dicapai dalam pengenalan akan diri yaitu pribadi Yesus Kristus. Sebagaimana panggilan Kierkegard, doa kita bagi saudara-saudara kaum homoseksual agar mereka dapat beriman kepada Tuhan Yesus Kristus sehingga mereka mulai "memproyeksikan dirinya, untuk kemudian berjuang diwujudkan" sehingga pada akhirnya "mulai dapat menemukan dirinya". Pada akhirnya, kekudusan dan kebenaran-keadilan Kristus dapat teraplikasikan dalam kehidupan setiap orang yang mengikuti-Nya.

Orang-orang yang telah mengakui Tuhan Yesus sebagai Tuhan dan Juruselamat mereka pasti menerima Roh Kudus yang tinggal dalam diri mereka dan memampukan mereka untuk mencapai kehidupan yang kudus. Penafsiran Douglas J. Moo terhadap surat Galatia, sebagaimana dipaparkan oleh Budiman Thia memerlihatkan kuasa Roh Kudus yang "memampukan orang percaya untuk mengatasi kuasa daging dan menstimulasi kasih kepada sesama sehingga dengan demikian menggenapi hukum Taurat". Dengan demikian, larangan hukum Taurat terhadap praktek homoseksualitas dapat dihindarkan oleh orang-orang yang telah dimenangkan oleh Kristus. Hal inilah yang disaksikan oleh Christopher Yuan, seorang mantan pelaku homoseksualitas yang telah 
ditebus dan dipulihkan oleh Kristus. ${ }^{42}$ Ia bersaksi pada bulan akhir April dan awal Mei 2017 di berbagai kota di Asia dalam Kebaktian Kebangunan Rohani yang diselenggarakan oleh Stephen Tong Evangelistic Ministries International.

42 Christopher Yuan \& Angela Yuan, Out of a Far Country: A Gay Son's Journey to God. A Broken Mother's Search for Hope (Colorado: Waterbrook, 2011). 